\title{
The Microstructure of Experience
}

ABSTRACT: I argue that experiences can have microphenomenal structures, where the macrophenomenal properties we introspect are realized by non-introspectible microphenomenal properties. After explaining what it means to ascribe a microstructure to experience, I defend the thesis against its principal philosophical challenge, discuss how the thesis interacts with other philosophical issues about experience, and consider our prospects for investigating the microphenomenal realm.

KEYWORDS: structure of experience, microphenomenal, introspection, panpsychism, luminosity, microstructure, microexperience

\section{Introduction}

When we think about the structure of the physical world, we distinguish the macrophysical realm from the microphysical realm. We take the macrophysical properties we perceive with the naked eye (or ear, nose, tongue, etc.) to be realized by microphysical properties beyond our perceptual grasp. Putting it another way, we take the physical world to have a microstructure.

Though this picture of the physical world is now familiar, it has not always been obvious. For a theorist of antiquity, ascribing a microstructure to the physical world would have been a radical and speculative hypothesis. Perception alone reveals only the physical world's macrostructure. To investigate its microstructure, we had to develop experimental methods, theoretical frameworks, and technology that enable us to discover more than what our unaided perceptual capacities reveal.

Our perceptual capacities put us in contact with physical properties of the external world. Our introspective capacities, on the other hand, put us in contact with phenomenal properties of our own experiences. But whereas the idea that the physical world has a microstructure is now taken for granted, the idea that our own experiences might have microstructures is widely dismissed. What would it even mean for the phenomenal properties we introspect to be realized by nonintrospectible microphenomenal properties? The following quotation from Barry Dainton illustrates this skepticism:

There is no reason to think phenomenal objects decompose into anything akin to the micro-constituents of ordinary physical objects... . The only phenomenal parts possessed by a phenomenal object are those that are 
manifest in the experience itself . . . since phenomenological inquiry is restricted to the level of appearances. (Dainton 2000: 95)

According to philosophical orthodoxy, experiences are not the kinds of things that can have microstructures. Since there is no appearance-reality distinction for experiences, there seems to be no room for a non-introspectible realm of microphenomenal properties. In fact, it is hard even to find explicit arguments against the idea of microphenomenal structure, for the impossibility of such a view is often taken to be more or less self-evident. ${ }^{\mathrm{I}}$

The central thesis of this paper is that experiences can have microphenomenal structures. To defend this claim, I argue that the following hypothesis is philosophically defensible:

MICROSTRUCTURE: Our experiences have microphenomenal structure.

Whether or not MICROSTRUCTURE is true is largely an empirical matter, and I will later argue that we do not yet have the tools for empirically evaluating the hypothesis. But I believe that the philosophical grounds for dismissing it are weak and that the hypothesis deserves serious exploration. Furthermore, recognizing MICROSTRUCTURE as a live option has important ramifications for consciousness research. Not only does it challenge our conventional assumptions about the structure of experience, but it also has implications for issues such as which phenomenal properties are fundamental, what the physical correlates of experience might be, the investigation of consciousness, and the limits of introspection.

In section I, I characterize what it would mean for our experiences to have microphenomenal structures. In section 2, I address the principal challenge for MICROSTRUCTURE. In section 3, I discuss specific versions of MICROSTRUCTURE. In section 4 , I consider our prospects for investigating the microphenomenal realm.

\section{Microstructure}

What is it for a domain to have a microstructure? In brief: the observable macroproperties of the domain are realized by unobservable microproperties of that domain. It is easy to see how our default picture of the physical world satisfies this criterion: the macrophysical properties of tables, chairs, and watermelons are realized by microphysical properties of molecules, atoms, and particles. This section articulates what it means to ascribe a microstructure to experiences.

\section{I.I Microphenomenal Properties}

A phenomenal property is a property that characterizes the phenomenal character of an experience. In other words, phenomenal properties are the subjective, qualitative

\footnotetext{
${ }^{\text {I }}$ Some philosophers have discussed microstructure in the context of panpsychism (see Strawson 2006, Chalmers 2013, and Goff 2017). Those discussions overlap with the issues discussed in this paper, but the aims and scope are different. This paper focuses on microstructure as a thesis about the structure of experience, independent of its relation to issues about the mind-body problem. Later in the paper, I explain in more detail why microstructure and panpsychism are independent theses.
} 
properties that characterize what it is like to have an experience. If our experiences have microphenomenal structure, then the macrophenomenal properties we introspect (such as the properties characterizing color experiences, pains, and so forth) are realized by non-introspectible microphenomenal properties.

What is it for a property to be microphenomenal? To answer this question, it is useful to think first about what it is for a property to be microphysical. The obvious criterion is that microphysical properties are unobservable via our basic perceptual capacities. But while this condition is necessary, it is not sufficient. There are many physical properties, such as certain properties of large electromagnetic fields or of physical objects outside of our light cone, that are imperceptible but not microphysical. The other criterion needed is that microphysical properties also realize the macrophysical properties we perceive. By analogy, microphenomenal properties are non-introspectible phenomenal properties that realize the macrophenomenal properties we introspect.

Some might argue that a third criterion on microproperties is that they are properties of small entities. After all, the canonical examples of microphysical properties are properties of particles, atoms, and molecules. However, there are two reasons that favor leaving out size constraints in the characterization of microproperties. First, large entities also have microproperties. For example, the property that characterizes the precise atomic configuration of the Earth at this moment is a microphysical property of the Earth. Second, it is unclear how to apply the notion of size to experiences. The sense in which my visual experience of a particular object is 'smaller' than my total visual experience is arguably distinct from the notion of size we apply to physical objects.

\section{I.2 Introspection}

We can take introspection to be the first-person knowledge acquisition process by which we form judgments about our occurrent experiences. This characterization is largely neutral, leaving open a range of views about the nature and mechanisms of introspection. For those skeptical that there is any single proprietary process by which we form judgments about our own experiences, we can instead talk about whatever set of processes 'introspection' denotes. For our purposes, it also does not matter much whether we take the objects of introspection to be experiences, phenomenal properties, or phenomenal facts. And while I sometimes draw analogies between introspection and perception, that should not be taken to suggest that introspection is a kind of inner perception. More generally, MICROSTRUCTURE is consistent with holding that there are important epistemic asymmetries between perception and introspection. For example, even if one accepts that our experiences have microphenomenal realizers, one could still think that introspection is immune to certain kinds of error that perception is susceptible to (such as illusions and hallucinations).

Whereas introspection is a type of knowledge acquisition process, introspectibility is a matter of being able to acquire a piece of knowledge on the basis of introspection. Some have been tempted to think that properties that characterize what it is like to have an experience must be coextensive with properties that are introspectible. But that is a substantive claim, since introspectibility and phenomenality are specified 
by different theoretical roles: a property is phenomenal just in case it characterizes what it is like to have an experience, whereas a property is introspectible by a subject just in case that subjects can know on the basis of introspection that their experience instantiates that property. In section 2, I discuss some cases showing how phenomenal character comes apart from introspectibility.

Now we are in a better position to understand what demarcates the micro-macro boundary. In the case of the physical world, the boundary between the microphysical and macrophysical is fixed by the actual perceptual capacities of normal human subjects. In the case of experience, the boundary between the microphenomenal and macrophenomenal is fixed by the actual introspective capacities of normal human subjects. In both cases, the micro-macro distinction tracks the kinds of properties that normal human subjects are actually sensitive to. And in both cases, it is plausible that the boundary is vague and does not pick out a joint in nature. In fact, in section 2, I discuss some examples of phenomenal properties that plausibly lie in the borderline region between microphenomenal and macrophenomenal.

It is possible that microphenomenal properties are introspectible in principle even though normal human subjects lack the requisite introspective capacities. By analogy, even though microphysical properties are imperceptible, we can imagine creatures (or enhanced human subjects) with perceptual capacities that enable the perception of microphysical properties. In section 4 , I briefly discuss the analogous possibility of creatures (or enhanced human beings) with introspective capacities that enable the introspection of microphenomenal properties.

\section{I.3 Appearance and Reality}

Since there seems to be no appearance-reality distinction for experiences, it may be puzzling how to make sense of microphenomenal properties. In the case of the perception, microphysical properties do not figure into how the physical world appears to us. But if we are interested in appearances themselves, then it does not make sense to talk about appearance properties that do not figure into the way things appear to us. Yet, that seems to be what microphenomenal properties must be.

The puzzle arises from an equivocation on the term 'appearance'. On the one hand, we could understand 'appearance' in a phenomenal sense, where appearances are a matter of phenomenal character. In this sense of 'appearance', it does not make sense to talk about phenomenal properties that do not figure into the way things appear to us. But MICROSTRUCTURE is not committed to an appearance-reality distinction in this sense: microphenomenal properties are phenomenal properties that characterize the phenomenal character of a subject's experience. On the other hand, we could understand 'appearance' in an epistemic sense, where appearances are a matter of the judgments a subject is inclined to make. MICROSTRUCTURE entails an appearance-reality distinction in this sense of 'appearance': a subject's having a certain experience does not guarantee that the subject makes the right judgments about that experience. But there is nothing contradictory about an appearance-reality distinction for experiences in this sense. Once we distinguish these two different senses of 'appearance', the puzzle dissolves. 
Nevertheless, the puzzle points to one of the disanalogies between microphenomenal properties and microphysical properties. Whereas microphysical properties do not make a difference to our experiences at all (in that they do not figure into the contents of our experiences), microphenomenal properties do make a difference to our experiences (in that they partially characterize the phenomenal character of our experiences). Despite this, microphenomenal properties still satisfy the theoretical role associated with microscopic properties discussed previously: namely, being non-introspectible phenomenal properties that realize the macrophenomenal properties we introspect.

\section{I.4 An Analogy}

Some might still find it hard to understand how non-introspectible phenomenal properties could contribute to the phenomenal character of experience. Perhaps an analogy will help. Think about a series of photographic layers superimposed on top of each other so that they collectively form an image. Each layer makes its own contribution to the character of the image-some layers add a certain texture, some add a certain shade of color, and so on. Since the layers are stacked on top of each other, they are seamlessly blended together. When we perceptually observe the image, we do not discern the individual layers; rather, we see a unified image. Nevertheless, each layer contributes to how the image appears to us. If a layer were removed, our perceptual experience would change. Similar examples would also work with other kinds of sensory modalities: consider, for example, a sound sample with multiple layers, a culinary dish with a variety of flavors, or a perfume containing a blend of scents. Analogously, microphenomenal properties might each make their own contribution to the overall phenomenal character of our experience even though we may be unable to individuate them introspectively when they are combined with other microphenomenal properties.

\section{I.5 Philosophical Motivations}

I mentioned at the beginning of the paper that MICROSTRUCTURE is an empirical thesis that we are not yet in a position to assess. But there are also some philosophical motivations for MICROSTRUCTURE. These philosophical considerations are speculative, but it is worth mentioning them briefly.

First, MICROSTRUCTURE is implied by certain views on the mind-body problem. Most notably, Microstructure is entailed by constitutive panpsychism, the view that fundamental physical entities have microexperiences that constitute the macroexperiences of macrosubjects. I discuss the relationship between MiCROSTRUCTURE and panpsychism in more detail in section 3. More generally, MICROSTRUCTURE is supported by any view about the mind-body problem that takes phenomenal properties to correspond to relatively low-level physical properties.

Second, MICROSTRUCTURE provides a basis for solving the grain problem (Lockwood I993), the problem of explaining the mismatch between the structure of our experiences (as revealed by introspection) and the structure of the physical correlates of experience. For example, our experiences sometimes seem to have 
continuous structures while the physical correlates of experience seem to have discrete structures. This discrepancy in structure is puzzling, especially for theories that entail that the structure of an experience cannot outstrip the structure of its physical correlates. But if MICROSTRUCTURE is true, then our experiences might turn out to have discrete structures at the microphenomenal level even if introspection leads us to believe that they have continuous structures.

Third, MiCROSTRUCTURE has implications for phenomenal similarity. When two experiences are phenomenally similar, they must be similar in virtue of sharing some phenomenal properties. But there are cases where we have reason to think that two experiences are similar even though they do not seem to share any macrophenomenal properties. For example, one class of such examples is crossmodal correspondences, or associations between seemingly unrelated basic sensory features across different sensory modalities (e.g., bright objects and high pitches). A natural hypothesis is that crossmodally paired experiences are phenomenally similar. But this hypothesis is tenable only if MICROSTRUCTURE is true because crossmodally paired experiences seem to have no macrophenomenal properties in common. ${ }^{2}$

Fourth, MICROSTRUCTURE opens up the possibility for small-palette, the thesis that there is a small number of fundamental phenomenal properties. I believe this is the most intriguing philosophical motivation for MICROSTRUCTURE, in part because it has the potential to reshape significantly the way we think about the structure of experience. I discuss the relationship between MICROSTRUCTURE and small-palette in more detail in section 3 .

\section{Structure Luminosity}

Philosophers have largely been skeptical of MICROSTRUCTURE, often assuming that experiences cannot have microstructures. The principal basis for this skepticism is epistemological. While it now seems obvious that the way the physical world really is need not be the same as the way it appears, it is less obvious how to understand such a distinction for experiences. The following quotation from Philip Goff illustrates the sentiment behind this skepticism:

Surely, you know exactly what your pain is-what it is for someone to feel pained in precisely that way-just by attending to pain and thinking about [it] in terms of how it feels. There is nothing in any way hidden from you about the reality of how you're feeling. . . . And that's because the feeling is 'right there' for you. (Goff 2017: I08)

Is there a principle that can provide the basis for an epistemological challenge against MICROSTRUCTURE? At first pass, the challenge seems to be motivated by LUMINOSITY, the thesis that if a subject has an experience, then that subject is in a position to know any phenomenal fact about that experience. However, LUMINOSITY is a thesis that many

\footnotetext{
${ }^{2}$ See Marks (I987) for a well-known experimental study on audiovisual correspondences, Spence (20I I) for a general overview of crossmodal correspondences, and Parise (20I6) for a discussion of experimental paradigms and current issues. Notably, some researchers (such as Marks 1987) have used the term 'crossmodal similarities' to denote the phenomenon.
} 
contemporary philosophers reject. $^{3}$ Since MICROSTRUCTURE has been widely dismissed, LUMINOSITY is too controversial to capture the general challenge to MICROSTRUCTURE. Instead, we need a more targeted thesis:

STRUCTURE LUMINOSITY: If a subject introspects an experience, then that subject is in a position to know the phenomenal realizers of that experience.

To know the phenomenal realizers of an experience is to know which experiences realize that experience. For example, my total perceptual experience is realized by my visual experience, auditory experience, and so forth. According to sTRUCTURE LUMINOSITY, introspecting my total perceptual experience puts me in a position to know that it is realized by my different sensory experiences. If an experience has no phenomenal realizers, then we can take STRUCTURE LUMINOSITY to entail that we are in a position to know that.

STRUCTURE LUMINOSITY is more modest than LUMINOSITY. It is restricted to facts about which experiences realize other experiences, rather than ranging over all phenomenal facts. And it is restricted to experiences that subjects introspect, rather than ranging over all experiences. These qualifications enable us to set aside many of the traditional objections to LUMINOSITY, which largely concern nonideal conditions for introspection, such as introspection of experiences outside the focus of one's attention, or in the periphery of one's visual field, or in comparison to extremely similar experiences. Since STRUCTURE LUMINOSITY is immune to some of the traditional objections against LUMINOSITY, it is a more defensible thesis.

At the same time, STRUCTURE LUMINOSITY precisely targets the most counterintuitive consequence of MICROSTRUCTURE: namely, that even in the best conditions for introspection, our experiences can have more structure than what we can introspect. With STRUCTURE LUMINOSITY, we can develop a general epistemological challenge to MICROSTRUCTURE:

PI: If a subject introspects an experience, then that subject is in a position to know the phenomenal realizers of that experience.

P2: If Microstructure is true, then our experiences have microphenomenal realizers.

$\mathrm{P}_{3}$ : Introspecting our experiences does not put us in a position to know that our experiences have microphenomenal realizers.

C: Microstructure is false.

The first premise is STRUCTURE LUMINOSITY. The second premise is justified by the definition of Microstructure. And the third premise is justified by basic introspection and the definition of microphenomenal realizers. I believe this argument captures the principal challenge to MICROSTRUCTURE.

\footnotetext{
${ }^{3}$ The formulation of LuMINOSITY stated here differs slightly from the canonical formulation from Williamson (2000) though the differences do not matter for the purposes of this paper. See Williamson (2000) for a classic argument that there are no phenomenal states such that whenever one is in that state, one is always in a position to know that one is in that state.
} 
I will argue that the first premise-STRUCTURE LUMINOSITY-is false. The best way to see why it is false is by appeal to some empirical considerations. In what follows, I present three cases against STRUCTURE LUMINOSITY. ${ }^{4}$

\section{I Pain Asymbolia}

When introspecting their pains, most people are inclined to think that pain is a simple, unstructured phenomenal property. But pain asymbolia, a condition caused by damage to the posterior insula of the brain's cortex indicates otherwise (Grahek 2007). Pain asymbolics report experiencing pain sensations without feeling motivated to stop those sensations. For example, if a pain asymbolic's hand is placed in a bucket of ice water or on a hot stove, the subject will report experiencing the pain sensations without unpleasantness.

The standard explanation of pain asymbolia is that pain experience has two separable components: a sensory component (corresponding to the pain sensation) and an affective component (corresponding to the unpleasantness). This view takes the reports of pain asymbolics at face value and has been defended by both philosophers and scientists. ${ }^{5}$ The idea is that the pain experiences of pain asymbolics retain the sensory component but lack the affective component. Because of this, pain asymbolics do not feel the immediate motivation to withdraw from painful stimuli even though stimulation of their nociceptors still causes them to feel sensations. Figure I illustrates this structured model of the structure of pain experience:

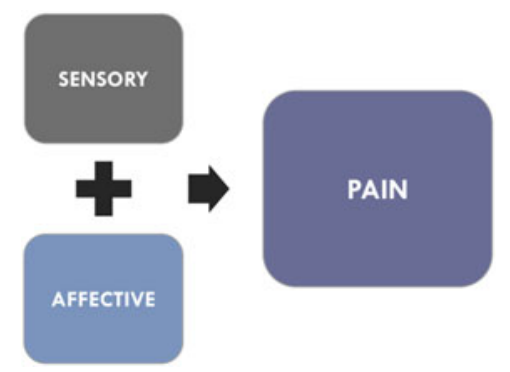

Figure I. The structured model of pain experience.

\footnotetext{
${ }^{4}$ See Roelofs (20I4) for discussion of some of these same cases in a different though related context: namely, in regard to the palette problem for Russellian monism.

${ }^{5}$ See Grahek (2007) for a comprehensive scientific and clinical discussion of pain asymbolia. See Kupers et al. (I99I) for evidence of similar reports from morphine patients. For defenses of the structured model of pain experience, see Dennett (I978), Hardcastle (I997), Price (2000), and Grahek (2007). For a recent criticism of this interpretation, see Klein (2015). Note that in order to defend STRUCTURE LUMINOSITY, one must not only establish that the structured model of pain experience is false, but also that we are in a position to know it is false solely on the basis of introspection.
} 
If STRUCTURE LUMINOSITY is true, then subjects are in a position to know the phenomenal realizers of their pain experiences. But even though pain experiences are both salient and ubiquitous, we did not learn about their structure until evaluating the evidence from pain asymbolics. ${ }^{6}$ As Grahek (2007) puts it, even though 'pain appears to be simple, homogenous experience', its components 'can become disconnected and therefore, much to our astonishment, they can exist separately'. Consequently, STRUCTURE LUMINOSITY is false.

\subsection{Pixel Mosaic}

Take a look at the pixel mosaic below:

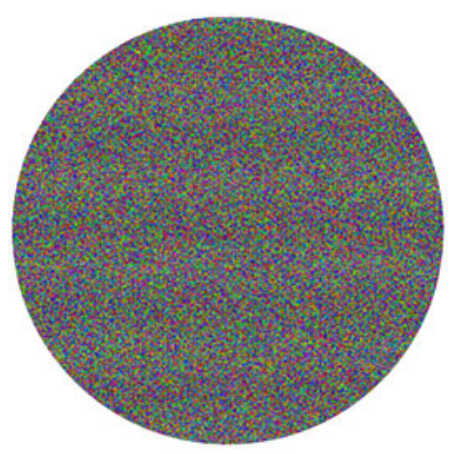

Figure 2. A pixel mosaic.

Consider your visual experience as you stare at the center of the pixel mosaic. Your overall visual experience of the pixel mosaic is realized by numerous local visual experiences corresponding to different parts of the pixel mosaic. But it is unlikely that introspecting your visual experience will put you in a position to identify those phenomenal realizers. Even if you are able to know some coarse-grained facts about those phenomenal realizers, such as the fact that they each represent arrays of pixels, you are unable to know precisely which local visual experiences realize your overall visual experience. Hence, you are not in a position to know the phenomenal realizers of your overall visual experience.

Some might argue that you are in a position to identify each individual phenomenal realizer even if you are not in a position to know the total collection that realizes your overall visual experience. But even such piecemeal knowledge is arguably unattainable. Can you tell which color your visual experience represents

\footnotetext{
${ }^{6}$ The structured model of pain experience is corroborated by another case involving a patient with a post-central lesion, where stimulation of the patient's hand caused him to report experiencing a sensation that was not painful but was 'clearly unpleasant' and which he 'wanted to avoid'. The researchers investigating this patient have argued that this is a case where the affective component of pain experience was present in the absence of the sensory component. Taken along with pain asymbolia, this is evidence of a double dissociation between the two components of pain. See Ploner, Freund, and Schnitzler (1999) for the reports and discussion of this case.
} 
the pixel at the top-left part of the mosaic as being, whether each individual phenomenal realizer is stable over time or slightly changing in character as your attention shifts, or even what the most basic phenomenal realizers are in this case? Even if you have excellent introspective abilities, you are unlikely to be able to distinguish the maximally determinate phenomenal properties characterizing your current experiences from the other nearby maximally determinate phenomenal properties that represent different configurations of pixels. The upshot is that you are not in a position to know the phenomenal realizers of your overall visual experience. Consequently, STRUCTURE LUMINOSITY is false.

\subsection{Flavor Experience}

When you have a flavor experience, are you in a position to identify its gustatory and olfactory realizers? Consider, for example, the flavor experiences induced by 'ripe mangoes, fresh figs, lemon, cantaloupe melon, raspberries ... green olives, ripe persimmon, onion, caraway, parsnip, peppermint, aniseed, cinnamon, fresh salmon' (see Sibley [2006] for even more examples of flavors). Even careful introspection does not reveal what the phenomenal realizers of those experiences are. In fact, flavor experiences often seem simple and unstructured. This point is well articulated by Smith (2013) when he says that even though flavor perception is multimodal, flavor experiences 'can strike us as whole, unified percepts', and 'on the basis of that phenomenology, we are often unable to distinguish the sensory components that feed into such experiences'.

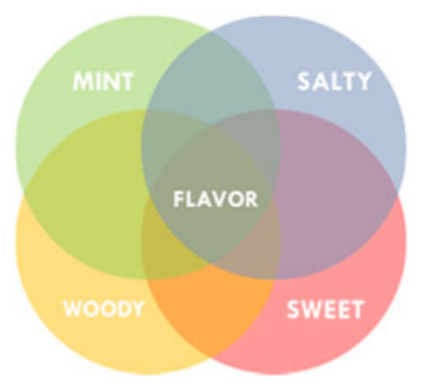

Figure 3. Flavor experiences are realized by olfactory and gustatory experiences.

Some might contend that flavor experiences really are simple. But there is compelling reason to think that flavor experiences are at least partially realized by gustatory and olfactory experiences. The science of flavor perception indicates that flavor perception involves a combination of olfactory and gustatory perception and perhaps somatosensory and hedonic experiences as well. In particular, differences in gustatory and olfactory perception systematically track differences in flavor experience (see Auvray and Spence [2008] and Spence, Auvray, and Smith [2015] for overviews of the science of flavor perception and implications for flavor phenomenology). Even setting aside the empirical 
evidence, it is easy to grasp that flavor experiences are structured with some experimental phenomenology: pinch your nose while eating a food, and you will notice that some aspects of flavor experience are lost when the contribution from olfaction is removed.

Some might object that it is sometimes possible to identify the phenomenal realizers of one's flavor experiences. For example, wine connoisseurs can arguably discriminate a rich range of components within their wine experiences. But few subjects can do this with any degree of reliability, and it is plausible that nobody can identify every basic gustatory and olfactory realizer for any flavor experience. Even among experts, the most careful introspection of one's flavor experience does not put one in a position to know, in precise and complete detail, that experience's gustatory and olfactory realizers. The upshot is the same as in the other cases: STRUCTURE LUMINOSITY is false.

\subsection{Objections}

I have argued against STRUCTURE LUMINOSITY, and in doing so I have defended MICROSTRUCTURE. How might a proponent of STRUCTURE LUMINOSITY respond to my arguments?

A first objection is that the cases above do not exhibit genuine examples of microphenomenal properties. However, this objection misconstrues the dialectic. The purpose of the cases is to show that STRUCTURE LUMINOSITY is false. By consequence, the principal challenge to MICROSTRUCTURE is unsound. The question of whether the phenomenal realizers discussed above are microphenomenal is independent of that dialectical point. On that question, though, I am inclined to think that the cases I have discussed lie within the borderline region between microphenomenal and macrophenomenal.

A second objection is that subjects do know the realizers of the phenomenal properties they introspect, but do so only under the guise of different concepts. For example, in the case of pain asymbolia, one might think that subjects know that ordinary pain experiences have a sensory and an affective component even if they do not have concepts that pick out those specific components. However, if this response is tenable, it becomes unobvious that STRUCTURE LUMINOSITY is inconsistent with MICROSTRUCTURE in the first place. The microtheorist could argue that subjects do know the microphenomenal realizers of their microphenomenal properties, but do so under the guise of different concepts.

A third objection is that subjects are in a position to know the realizers of their experiences even if they cannot actually acquire such knowledge. For example, in the case of the pixel mosaic, one might argue that you are in a position to know which maximally determinate phenomenal property characterizes your visual experience even if your introspective capacities do not actually enable you to acquire that knowledge. However, in my original formulation of microphenomenal properties, non-introspectibility concerns the actual introspective capacities of normal human subjects. If STRUCTURE LUMINOSITY abstracts away from those limitations, then the microtheorist could accept that subjects are in a position to know the microphenomenal realizers of their experiences while also holding that 
their introspective capacities do not actually enable them to acquire such knowledge. As before, this move deflates the force of the challenge by rendering STRUCTURE LUMINOSITY consistent with MICROSTRUCTURE.

A last objection is that these cases do not involve genuine phenomenal realizers. For example, one might argue that in the case of flavor experiences, the gustatory and olfactory components are not realizers of flavor experiences, but instead aspects of flavor experiences. The difference is a matter of fundamentality; realizers are grounders, whereas aspects are grounded. However, this objection employs a more theoretically demanding notion of 'realizer' than what I have in mind. As I will discuss in the next section, MicRostruCtURE builds in no claims about the direction of fundamentality. On the relevant understanding of 'realizer', the claim that flavor experiences have gustatory and olfactory phenomenal realizers is consistent with the latter being aspects of the former. Consequently, someone who thinks that experiences have microphenomenal aspects is still committed to a version of MICROSTRUCTURE.

\section{Microtheories}

A microtheory is a specific version of MICROSTRUCTURE. This section develops a taxonomy of different kinds of microtheories. The discussion will also further clarify what is built into MICROSTRUCTURE itself.

\section{I Scope}

Which classes of macrophenomenal properties have microphenomenal realizers? According to global microtheories, all macrophenomenal properties have microphenomenal realizers. These are the most ambitious versions of Microstructure. But there are also local microtheories according to which particular categories of macrophenomenal properties have microphenomenal realizers. Some might think that there are reasons for ascribing microphenomenal structure to some categories of experience but not others. For example, we could consider whether color experiences or auditory experiences or emotional experiences have microstructures, independently of whether a global thesis is true. In the middle are microtheories that take all but a privileged set of macrophenomenal properties to have microphenomenal realizers. For example, some might think that the phenomenal properties characterizing the unity of experience and the subjective character of experience cannot have microphenomenal realizers even though other kinds of macrophenomenal properties can.

It is plausible that empirical investigation of MICROSTRUCTURE would proceed by way of piecemeal investigation into particular domains of experience. If there is evidence that many local domains of experience have microphenomenal structures, then that may pave the way for a global microtheory. However, my principal aim has been to argue that ascribing microphenomenal structures to experiences is philosophically defensible in the first place. Because of this, I have 
focused on broad considerations concerning experience in general, rather than on specific considerations concerning local domains of experience.

\subsection{Metaphysical nature}

Whether one is a physicalist, dualist, idealist, or dual-aspect monist, one could be a microtheorist. Some might wonder whether physicalism entails that experiences have microstructures since physicalists think that experiences are ultimately realized by microphysical properties. However, MICROSTRUCTURE is a thesis about the phenomenal structure of experience, not about its structure simpliciter. While physicalists take experiences to have more structure than we can introspect, they might still think that there are only macrophenomenal properties.

What about panpsychism, the view that fundamental physical entities have phenomenal properties? Though it is common for panpsychists to talk about microphenomenal properties, panpsychism and MICROSTRUCTURE are independent theses. First, one could be a panpsychist macrotheorist. For example, one might hold that the microexperiences of fundamental entities stand in a causal, rather than a constitutive, relation to the macroexperiences of human subjects and that human experiences have only macrophenomenal structure. Or one might hold that the fundamental physical entity is the entire universe, that human experiences are aspects of the universe's cosmic experience, and that human experiences have only macrophenomenal structure. Conversely, one could be a non-panpsychist microtheorist. For example, one might think that only complex organisms are conscious, but that human experiences have microphenomenal structure.

While MiCROSTRUCTURE and panpsychism are independent, MICROSTRUCTURE is entailed by the most popular version of panpsychism: namely, constitutive micropsychism. According to this view, the macrophenomenal properties we introspect are realized by microphenomenal properties of microphysical entities. This means that by defending MICROSTRUCTURE, this paper has indirectly defended constitutive micropsychism: if constitutive micropsychism is false, it is not because it is untenable to ascribe microphenomenal structure to experience.

\section{$3 \cdot 3$ Subjects}

If there are microphenomenal properties, must there be microsubjects? MICROSTRUCTURE is a thesis about the structure of our own experiences, rather than a thesis about the existence of other subjects. Just as positing visual phenomenal properties does not commit us to visual subjects, positing microphenomenal properties does not commit us to microsubjects. Consider how you are currently undergoing a total perceptual experience, which is realized by your visual experience, auditory experience, and so forth. If MICROSTRUCTURE is true, then your experiences also have further microphenomenal realizers. But this does not entail anything about the existence of further subjects.

Some philosophers, such as Byrne (2009) and Nida-Rümelin (2018), have argued that phenomenal properties should be understood as properties of subjects, rather than as properties of experiences. Those who favor this framework might find it 
odd to take microphenomenal properties to be properties of human subjects. But remember that microproperties need not be properties only of microphysical entities. For example, the property specifying the exact atomic configuration of the Earth at this moment is a property of the Earth.

Some of the confusion may come from conflating two different definitions of microphenomenal properties. Sometimes the term 'microphenomenal property' is used to denote phenomenal properties of microphysical entities, such as in Chalmers (20I3). In contrast, I use the term 'microphenomenal property' to denote non-introspectible phenomenal properties that realize the macrophenomenal properties we introspect. These characterizations are doubly dissociable, for the reasons mentioned above in the discussion of panpsychism. And for the reasons discussed in section I, I believe that my characterization of microphenomenal properties better parallels how we think about microphysical properties.

\section{$3 \cdot 4$ Fundamentality}

There are two questions about fundamentality that are worth examining in conjunction. First, are total experiences grounded in experiential parts? Second, are macrophenomenal properties grounded in microphenomenal properties?

The first issue concerns fundamentality with respect to mereology of experiences. According to atomism, experiential parts ground total experiences. Under this view, the fundamental phenomenal properties are properties of experiential parts. This would be analogous to the position of an atomist about the physical world that takes the fundamental physical properties to be properties of particles. In contrast, according to holism, experiential parts are grounded in total experiences. Under this view, the fundamental phenomenal properties are properties of total experiences. This would be analogous to the position of a holist about the physical world that takes the fundamental physical properties to be properties of the entire universe. Both of these views are consistent with taking experiences to have microphenomenal structure, just as atomism and holism about the physical world are both consistent with taking the physical world to have microphysical structure (see Schaffer (2010) for discussion of holism about the physical world, and Lee (2015) for discussion of atomism and holism about experiences).

The second issue concerns fundamentality with respect to granularity of phenomenal properties. According to microprimitivism, the fundamental phenomenal properties are microphenomenal. Some might be tempted to think that MICROSTRUCTURE entails microprimitivism. But MICROSTRUCTURE is also consistent with macroprimitivism, the view that the fundamental phenomenal properties are macrophenomenal. To get a grip on how macrophenomenal properties could ground microphenomenal properties, think about the relationship between color versus hue, saturation, and brightness. Some think that color properties are more fundamental than hue, saturation, and brightness properties and that the latter are abstractions from the former. Similarly, a macroprimitivist microtheorist thinks that macrophenomenal properties ground microphenomenal properties because the latter are abstractions from the former. 
Consequently, ascribing microphenomenal properties to experience does not entail that the fundamental phenomenal properties are microphenomenal.

These two dimensions of fundamentality are independent. For example, an atomist could be a macroprimitivist. Under this view, the fundamental phenomenal properties are macrophenomenal properties of experiential parts. Conversely, a holist could be a microprimitivist. Under this view, the fundamental phenomenal properties are microphenomenal properties of total experiences. Once we recognize those two views are possible, it is easy to see that atomist microprimitivism and holist macroprimitivism are possible positions as well. And any of these views is consistent with microstructure, for the reasons discussed above. To put it succinctly, MICROSTRUCTURE is a thesis about how much structure experiences have, leaving open questions about which features of experience are fundamental. ${ }^{7}$ By disentangling these issues, we get a more precise understanding of what is built into MICROSTRUCTURE and a more fine-grained taxonomy of different views about the structure of experience.

\subsection{Palette}

How big is the base of phenomenal primitives? The most common view is large-palette, according to which there is a large number of phenomenal primitives. Large-palette is popular in part because it is often presumed to be the only game in town. If experiences have only macrophenomenal properties, then it is hard to avoid the conclusion that there is a very large number of phenomenal primitives. After all, it is implausible that all phenomenal properties could be grounded in a privileged set of macrophenomenal properties. McGinn (2006) captures this thought when he says that 'you cannot get pains from experiences of colours, or emotions from thoughts, or thoughts from acts of will.' Because of this, the phenomenal primitives are often presumed to be maximally determinate macrophenomenal properties, such as the phenomenal properties characterizing specific color experiences, specific pain experiences, specific olfactory experiences, and so forth. Following this way of identifying the phenomenal primitives, the number of phenomenal primitives quickly multiplies.

However, MICROSTRUCTURE opens up the possibility for small-palette, the view that there is a small number of phenomenal primitives. If small-palette is true, then the rich variety of macrophenomenal properties we introspect is generated by a sparse set of fundamental phenomenal properties. To put it another way, small-palette is the thesis that all experiences are made of the same basic phenomenal ingredients. Macrophenomenal properties do not stand in the right grounding relations to each other to make small-palette viable, but MICROSTRUCTURE makes the possibility of small-palette more promising.

Some philosophers might contend that small-palette is dubious even if we accept MICROSTRUCTURE. On the face of it, our experiences are too diverse and variegated for

\footnotetext{
${ }^{7}$ In fact, it is even possible to accept MICROSTRUCTURE while holding that there are no phenomenal primitives. For example, one might think that experience is gunky and that every phenomenal property is grounded in more fundamental phenomenal properties.
} 
all of them to be made of the same basic phenomenal ingredients. But consider how theorists of antiquity might have been likewise dubious of small-palette theses about the physical world. Such theorists might even have thought that there were principled philosophical reasons for ruling out such a hypothesis: they might have argued that solids can generate only more solids and that liquids can generate only more liquids or that intangible substances like wind cannot be made from the same things as material substances like earth. In hindsight, it is obvious that these arguments are unsound. But our current epistemic perspective on the physical world obscures how unobvious this once was. Our inquiry into experience remains in early stages, and our epistemic perspective on experience is plausibly closer to that of theorists of antiquity speculating about the physical world than that of contemporary scientists building upon well-developed scientific foundations. Because of this, I believe we ought to be epistemically humble about the prospects for small-palette so long as MICROSTRUCTURE is a live option. ${ }^{8}$

\section{Investigating the Microphenomenal Realm}

Suppose that our experiences do have microstructures. What are our prospects for investigating the microphenomenal realm? This section considers two key questions about this issue. First, what are the methodological challenges in discovering microphenomenal properties? Second, what are our cognitive limitations in forming microphenomenal concepts?

\section{I Methods}

The methodological challenges concerning investigation of microphenomenal properties stem from two main sources. First, there are problems that arise from microphenomenal properties being phenomenal. Second, there are problems that arise from microphenomenal properties being microscopic. I will discuss each of these briefly and then problems for the investigation of microphenomenal properties more generally.

The principal challenge for investigating phenomenal properties is that attaining knowledge of phenomenal properties requires first-person (in addition to third-person) methods. Even if we collect all the relevant third-person data, we still would not gain knowledge of phenomenal properties unless we also integrated the third-person data with first-person data. But collecting reliable first-person data is difficult-it is often unclear what the best methods are for producing such data in the first place and how to best interpret the data that is available.

The principal challenge for investigating microscopic properties is that attaining knowledge of microscopic properties requires tools that transcend our basic observational capacities. When we investigate the microphysical realm, we cannot

\footnotetext{
${ }^{8}$ Of course, there are many views where the physical primitives include physical properties that are not obviously microphysical, such as properties of spacetime. And there are some views where it is not clear whether there are any microphysical primitives, such as views where the fundamental physical properties are properties of the quantum state of the universe. I will set aside these views here.
} 
rely merely on our basic perceptual capacities. To investigate the microstructure of the physical world, we have had to develop experimental methods and technology designed to be sensitive to microphysical properties.

These two problems come together in the case of microphenomenal properties. Since microphenomenal properties are phenomenal, we cannot investigate them without using first-personal methods. But since microphenomenal properties are microscopic, we cannot investigate them using our basic observational capacities. What we need to investigate microphenomenal properties are first-personal methods that transcend our basic introspective capacities.

One possibility is to extend current first-person methods that go beyond basic introspection. Perhaps we could better develop the method of phenomenal contrast, where two minimally different experiences are contrasted to isolate a particular phenomenal property. ${ }^{9}$ Or we could examine more dissociation cases, such as in the case of pain asymbolia, where two phenomenal properties that we thought were inextricably connected come apart. Or we could conduct data analyses on introspective judgments that aim to extract independent dimensions of variation from a set of data. However, the problem is that all of the above methods are already used for investigating experience, and it is not obvious that better application of such methods would yield knowledge of microphenomenal properties.

What about our prospects for developing technology to enhance the investigation of experience? The development of technology that enhances our investigation of the physical world has played a crucial role in our understanding of the microphysical realm. Perhaps what is needed to investigate the microphenomenal realm is firstperson technology that enhances first-person investigation of experiences. For example, perhaps subjects might acquire better introspective capacities with advanced training, or specially designed drugs, or artificial alterations to their cognitive architectures.

Of course, the prospect of developing first-person technology raises a number of philosophical challenges. These include how we would know we are altering a subject's introspective capacities (rather than the phenomenal character of the subject's experience), how first-person data about microphenomenal properties might be stored in a format accessible to subjects other than the one undergoing the experience, and how we could design first-person technology in the first place, given that the effects of such technology would be directly observable only by the subject using the technology. In order to gain traction on these issues, we need to acquire a better understanding of the nature and mechanisms of introspection and to develop better media for storing and communicating first-person data. On the whole, I am cautiously optimistic about the prospects for developing technology to enhance first-person investigation, ${ }^{\text {IO }}$ though I believe we are not yet in a position to assess whether such methods would enable us to confirm or disconfirm MICROSTRUCTURE empirically.

\footnotetext{
${ }^{9}$ See Siegel (20II) for a discussion and defense of the method of phenomenal contrast.

${ }^{\text {Iо }}$ In Lee (manuscript under review), I will discuss the prospects for first-person technology in more detail.
} 


\subsection{Concepts}

In addition to the issues concerning the discovery of microphenomenal properties, there are also issues concerning our ability to form concepts for microphenomenal properties.

We can distinguish between two kinds of phenomenal concepts. Pure phenomenal concepts are concepts that pick out phenomenal properties directly via their phenomenal character. When I think about what it is like to have a phenomenal red experience, for example, I am deploying a pure phenomenal concept. Impure phenomenal concepts are concepts that pick out phenomenal properties via definite description or linguistic deference. When I think about the experience typically had by normal human subjects when they see red objects, I am deploying an impure phenomenal concept. Before Mary (from Jackson [I982]'s knowledge argument) leaves her black and white room, she has rich impure concepts of phenomenal redness but no pure concept of phenomenal redness. For a more extended discussion of phenomenal concepts, see Chalmers (2003).

What are the prospects for acquiring pure microphenomenal concepts? It is plausible that acquiring a pure phenomenal concept of a phenomenal property requires being able to introspect that property. For example, congenitally blind persons cannot acquire pure phenomenal concepts of phenomenal redness because they do not have visual experiences that they can introspect. Likewise, it is hard to see how normal human subjects could acquire pure microphenomenal concepts given that normal human subjects cannot introspect microphenomenal properties. ${ }^{\text {II }}$

Perhaps another way of forming pure phenomenal concepts is through extrapolation. For example, even if one has never had an experience of a specific shade of blue (and so has never introspected that phenomenal property), perhaps one could still form a pure phenomenal concept of that phenomenal property by extrapolating from the phenomenal blue experiences one has had. But even if extrapolation is possible, it is implausible that we could extrapolate from our pure macrophenomenal concepts to pure microphenomenal concepts.

What about impure microphenomenal concepts? Even if Mary cannot acquire a pure concept of phenomenal redness, she can still acquire rich impure concepts of phenomenal redness. Similarly, even if many pure microphenomenal concepts are out of reach, perhaps we could still acquire impure microphenomenal concepts. However, these cases might be disanalogous. Mary's impure concept of phenomenal redness is substantive because she has substantive theoretical knowledge about phenomenal redness. But our epistemic position with respect to microphenomenal properties is quite different from Mary's epistemic position with respect to phenomenal colors. Mary does not know the phenomenal character of phenomenal redness, but she knows many other facts about phenomenal redness. In contrast, we lack both knowledge of the phenomenal character and theoretical knowledge of microphenomenal properties. For example,

\footnotetext{
${ }^{\text {I I }}$ It is worth noting that this is not a problem specific to microphenomenal properties. After all, it is plausible that we are also unable to acquire pure phenomenal concepts for many phenomenal properties beyond the space of human experiences.
} 
we do not know what theoretical roles particular microphenomenal properties play beyond that of realizing macrophenomenal properties.

If we could develop first-person technology to enhance our introspective capacities, then we might be able to acquire pure microphenomenal concepts. And if we could attain more theoretical knowledge about microphenomenal properties, then we might be able to acquire more substantive impure microphenomenal concepts. But both of these prospects require us to address the methodological challenges discussed previously. The methodological issues and the conceptual issues intertwine-how substantive our concepts of microphenomenal properties could be may depend upon the extent to which we can surmount the methodological challenges.

Though empirically investigating MICROSTRUCTURE may be challenging, it is worth remembering that we are still at the early stages of exploring the structure of experience. Our epistemic position with respect to the structure of experience is like the epistemic position of theorists of antiquity with respect to the structure of the physical world. Perhaps just as theorists of antiquity were not in a position to appreciate the tools and methods we have developed for investigating the physical world, we are not in a position to appreciate the tools and methods that could be developed for investigating experience. Perhaps in the future ingenious new ways of investigating experience will be devised, and we will explore the depths of the microphenomenal realm.

ANDREW Y. LEE (C)

NEW YORK UNIVERSITY andrewyuanlee@gmail.com

\section{References}

Auvray, M., and C. Spence. (2008) 'The Multisensory Perception of Flavor'. Consciousness and Cognition, I7, Iо16-3 I.

Byrne, Alex. (2009) 'Experience and Content'. Philosophical Quarterly, 59, 429-5I.

Chalmers, David J. (2003) 'The Content and Epistemology of Phenomenal Belief'. In Quentin Smith and Aleksandar Jokic (eds.), Consciousness: New Philosophical Perspectives (Oxford: Oxford University Press), 220-72.

Chalmers, David J. (2013) 'Panpsychism and Panprotopsychism'. The Amberst Lecture in Philosophy, 8, I-35. Available at: http://www.amherstlecture.org/chalmers20I $3 /$.

Dainton, Barry F. (2000) Stream of Consciousness: Unity and Continuity in Conscious Experience. London: Routledge.

Dennett, D. C. (I978) 'Why You Can't Make a Computer that Feels Pain'. Synthese, 38, 4I 5.

Goff, Philip. (2017) Consciousness and Fundamental Reality. New York: Oxford University Press. Grahek, Nikola. (2007) Feeling Pain and Being in Pain. 2d ed. Cambridge, MA: MIT Press.

Hardcastle, Valerie Gray. (I997) 'What a Pain is Not'. The Journal of Philosophy, 94, 38 I-409.

Jackson, Frank. (1982) 'Epiphenomenal Qualia'. Philosophical Quarterly, 32, I27-36.

Klein, Colin. (2015) 'What Pain Asymbolia Really Shows'. Mind, I24, 493-5 I6.

Kupers, R. C., H. Konings, H. Adriaensen, and J. M. Gybels. (I99I) 'Morphine Differentially Affects the Sensory and Affective Pain Ratings in Neurogenic and Idiopathic Forms of Pain'. Pain, 47, 5-I 2.

Lee, Andrew. (manuscript under review) 'First-Person Technology'. New York University.

Lee, Geoffrey. (2015) 'Experiences and their Parts'. In Bennett Hill (ed.), Sensory Integration and the Unity of Consciousness (Cambridge, MA: MIT Press), 287-322. 
Lockwood, Michael. (I993) 'The Grain Problem'. In Howard M. Robinson (ed.), Objections to Physicalism (Oxford: Oxford University Press), 27I-9I.

Marks, L. E. (I987) 'On Cross-modal Similarity: Auditory-visual Interactions in Speeded Discrimination'. Journal of Experimental Psychology: Human Perception and Performance, I3 $384-94$.

McGinn, Colin. (2006) 'Hard Questions: Comments on Galen Strawson'. Journal of Consciousness Studies, I3, 90-99.

Nida-Rümelin, Martine. (2018) 'The Experience Property Framework: A Misleading Paradigm'. Synthese, 195, 336I-87.

Parise, Cesare V. (2016) 'Crossmodal Correspondences: Standing Issues and Experimental Guidelines'. Multisensory Research, 29, 7-28. https://doi.org/IO.I I63/22 I34808-00002502.

Ploner, M., H. K. Freund, and A. Schnitzler. (I999) 'Pain Affect Without Pain Sensation in a Patient with a Postcentral Lesion'. Pain, 8I, 2 I I-I 4.

Price, Donald. (2000) 'Psychological and Neural Mechanisms of the Affective Dimension of Pain'. Science, 288, 1769-72.

Roelofs, Luke. (2014) 'Phenomenal Blending and the Palette Problem'. Thought: A Journal of Philosophy, 3, 59-70.

Schaffer, Jonathan. (20I0) 'Monism: The Priority of the Whole'. Philosophical Review, I I9, 3 I-76.

Sibley, Frank, J. Benson, B. Redfern, and J. Roxbee Cox, eds. (2006) Approaches to Aesthetics: Collected Papers on Philosophical Aesthetics. Oxford: Clarendon Press.

Smith, Barry. (2013) 'The Nature of Sensory Experience: The Case of Taste and Tasting'. Phenomenology and Mind Online Journal, 292-3 I 3.

Spence, C. (20II) 'Crossmodal Correspondences: A Tutorial Review'. Attention, Perception, and Psychophysics, 73, 97I-95. https://doi.org/I0.3758/sI34II4-0I0-0073-7.

Spence, C., M. Auvray, and B. Smith. (2015) 'Confusing Tastes with Flavours'. In D. Stokes, M. Fullford, and M. Matthen (eds.), Perception and Its Modalities (New York: Oxford University Press), 247-74.

Strawson, Galen. (2006) 'Realistic Monism: Why Physicalism Entails Panpsychism'. Journal of Consciousness Studies, I 3 3-3 I.

Williamson, Timothy. (2000) Knowledge and its Limits. Oxford: Oxford University Press. 